UNIVERSITÉ DE LAUSANNE - FACULTÉ DE BIOLOGIE ET DE MÉDECINE DÉPARTEMENT DE PSYCHIATRIE

Institut universitaire de Psychothérapie

Directeur : Professeur associé Jean-Nicolas Despland

\title{
Early Change In Maladaptive Defense Style and Development of The Therapeutic Alliance
}

\section{THESE}

Présentée à la Faculté de biologie et de médecine de l'Université de Lausanne pour l'obtention du grade de

\section{DOCTEUR EN MEDECINE}

par

Gilles Ambresin

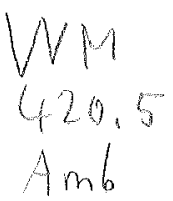

Médecin diplômé de la Confédération Suisse

Originaire d'Ollon (VD)

Lausanne 
Résumé

Cette étude examine les changements précoces dans le style Défensif Maladaptatif (SDM), le développement de l'alliance thérapeutique et la relation entre le SDM et l'alliance au cours d'une psychothérapie psychodynamique ultra-brève. Soixante-huit patients ambulatoires du centre de consultation psychiatrique et psychothérapique ont bénéficié d'une intervention psychodynamique en quatre séances. Les mesures des défenses et de l'alliance étaient effectuées à la première et à la dernière séance. Les patients qui ont débuté l'intervention avec une alliance faible et qui l'ont terminée avec une alliance haute (groupe de patients avec une alliance de croissance linéaire) ont diminué leur utilisation de défenses maladaptatives de manière significative au cours de la thérapie, alors que ce n'a pas été le cas pour les patients des groupes à alliances haute-stable et basse-stable. Les résultats ont montré qu'à la fin de l'intervention, le SDM et l'alliance étaient corrélés pour tous les patients. Cette corrélation intéressait plus particulièrement le groupe avec une alliance de croissance linéaire. Ces résultats suggèrent que le développement de l'alliance thérapeutique reflètent le travail de collaboration entre le patient et son thérapeute alors qu'ils essayent de mieux comprendre les causes de la crise du patient. Cette compréhension peut aider à réduire les défenses initialement activées pour permettre au patient de se défendre de $l^{\prime}$ anxiété et $d^{\prime}$ un sentiment de détresse. 
Running head: MALADAPTIVE DEEENSE STYLE AND THERAPEUTIC ALLIANCE

Early Change in Maladaptive Defense style and Development of the Therapeutic Alliance

Gilles Ambresin, Yves de Roten

University of Lausanne, Switzerland

Martin Drapeau

MCGill University, Canada

Jean-Nicolas Despland

University of Lausanne, Switzerland

This research was supported by the Swiss National Science Foundation, Grant No 3200B0-100706/1.

Address correspondence to : Gilles Ambresin, Institut Universitaire de Psychothérapie, Université de Lausanne, Site de Cery, Bât. les Cèdres, CH-1008 Prilly, Switzerland. Tel:

+41 (0) 21643 6111; Fax: +41 (0) 21 643.6593; Email:

gilles.ambresinechuv.ch 
Abstract

This study examined the early change in Maladaptive Defense style (MDS), the development of the Therapeutic Alliance, and the relationship between MDS and alliance, in a short psychodynamic intervention. Sixty-eight outpatients from a psychiatric clinic completed a four-session psychodynamic intervention. Defense and alliance measures were collected at the intake and the final session. Patients who began the intervention with a poor alliance but ended with a good alliance (linear growth therapeutic alliance group) significantly decreased their use of maladaptive defenses over the course of therapy, while patients in the high and low alliance groups did not. Results showed that at the end of the intervention, MDS and alliance were related across all patients. This relation concerned particularly the linear growth therapeutic alliance profile. These results suggest that the developing therapeutic alliance might reflect the collaborative work between the patient and the therapist as they try to understand the causes of the crisis. This understanding might help reduce maladaptive defenses that were initially activated to ward off anxiety and distress.

Keywords: Defense mechanisms, alliance, psychodynamic psychotherapy, crisis 
Early Change in Maladaptive Defense Style and Development of the Therapeutic Alliance

Defense mechanisms are usually described as relatively unconscious mechanisms activated to deal with painful feelings, thoughts, or situations caused by internal or external stressors. They can also be understood as basic mechanisms that pervade a wide variety of psychological phenomena (Perry \& Ianni, 1998). They can operate either as rigid, inappropriate mechanisms that inhibit change, or as processes that maximize adaptation. Understanding the patient's defensive functioning may assist the clinician in providing relevant psychological help.

Defense mechanisms have been empirically validated and grouped hierarchically according to the relative degree of ego maturity attributed to them (Vaillant, Bond, \& Vaillant, 1986). Perry (1990) retained seven levels of defensive functioning, from the more immature to the more mature: Action defenses, major image-distorting defenses (previously borderline defenses), disavowal, minor image-distorting defenses (previously narcissistic defenses), other neurotic defenses, obsessional defenses, and mature defenses. Each level includes 3 to 8 defenses. Though the immature defenses protect the patient from conflict, they are less adaptive. using them requires patients to constrict awareness of the 
stressor, a strategy that decreases their sense of personal choice and flexibility, and consequently often leads to negative outcomes. Mature defenses are considered to be more adaptive because they maximize the expression and gratification of wishes and needs, and provide patients with the freedom to choose how to cope with stressors, strategies that often minimize negative consequences. This hierarchy has been supported by numerous research findings. For example, action and image-distorting (immature) defenses have been associated with higher general levels of symptoms and greater impairment in psychological functioning (Perry \& Cooper, 1989) .

As a behavioral psychodynamic construct, defenses can be reliably identified by both observer-rated measures (e.g. Defense Mechanism Rating Scale (DMRS); Perry, 1990) and selfreport instruments (e.g. Defense style Questionnaire (DSQ); Bond, Gardner, Christian, \& Sigal, 1983).

Previous studies have used self-report questionnaires to detect changes in defensive functioning over the course of therapy. Akkerman, Lewin, and Carr (1999) examined long-term stability of ego defenses in a group of patients with major depression. They found that defenses were relatively stable during the first 6 months of therapy, but that after 2 years, patients who remained in treatment reported a continuing decrease in their use of immature defenses. Defense styles 
were also found to become more adaptive over time in long term dynamic psychotherapy with patients who presented with chronic and recurrent anxiety, depression and/or personality disorders (Bond \& Perry, 2004). Changes in defensive functioning - more specifically, an increase in the use of adaptive defenses and a decrease in the use of maladaptive defenses - were also seen in short term psychotherapy (Albucher, Abelson, \& Nesse, 1998; Mullen, Blanco, Vaughan, Vaughan, \& Roose, 1999; Lieberman, Wiitala, Elliott, McCormick, \& Goyette, 1998). Even in very brief treatment in 4 sessions, Drapeau, de Roten, Perry, \& Despland (2003) found that patients use more adaptive defenses at the end of the intervention with an increase of obssessional defenses and a decreased of narcissistic ones. However, Hersoug, Monsen, Havik, \& Hoglend (2002) found no change in defenses during a brief dynamic psychotherapy. Defensive functioning was assessed by the Defense style Questionnaire. The use of self-report measures to assess a mainly unconscious phenomenon is an important issue. Patients' self-reports are limited by their motivation at the time of responding, their openness, and by their self-awareness. However, according to Bond (1986), the DSQ is able to identify patients' defenses because it taps into conscious derivatives of these mostly unconscious processes. As such, patients may be aware of their defenses by having noticed when they failed, 
or because others may have previously pointed them out to them.

Early alliance building

Empirical evidence supports the association between early alliance and outcome in a psychotherapeutic setting.(Martin, Garske, \& Davis, 2000; Horvath \& Bedi, 2002). Early alliance can be determined either at a single session or as a developing process (Hilsenroth, Peters, \& Ackerman, 2004).

De Roten et al. (2004) examined early alliance building using the same sample as the current study. Based on Luborsky (1976), their cutoff score to differentiate between low and high alliance on the Helping Alliance questionnaire (HAq) was 17. Their analysis revealed three different profiles (see table 2): (1) a high stable alliance profile (HSa), with a mean alliance of 22.4 ; (2) a low stable alliance profile (LSa), with a mean alliance of 5.4; and (3) a linear growth alliance profile (LGa), with an alliance not different from the LSa profile at the session 1 and not different from the HSa profile at the session 4. These profiles predicted outcome more accurately than when the alliance was measured separately at each single session.

Defense and alliance

The relationship between defense mechanisms and the therapeutic alliance has rarely been addressed in the research literature. Bond and Perry (2004) reported that the initial 
maladaptive defense style score was significantly associated with lower mean alliance $(\underline{r}=-.53, \underline{p}<0.001)$. Their results are consistent with a meta-analysis of 11 studies that examined the impact of patients' pretreatment intrapersonal characteristics on the alliance (Horvath \& Luborsky, 1993). This study showed that patients with lower levels of defensive functioning were more likely to end up with a poor alliance in therapy. Vaillant (1992) suggested that intermediate-level defenses, such as rationalization, reaction-formation, and intellectualization, may interfere with an individual's capacity to engage in self-exploration. However, alliance development might be influenced by the therapist's interventions. In a time-limited dynamic psychotherapy, alliance and defenses appeared somehow related. Out of six patients, three patients who presented with a poor initial alliance developed a good final alliance. Unique to this subgroup, the therapist addressed the patients' defenses (Foreman \& Marmar, 1985). However, three studies reported that initial defensive functioning was not able to predict the quality of alliance development (Despland, de Roten; Despars, Stigler, \& Perry, 2001; Hersoug et al., 2002; Siefert, Hilsenroth, Weinberger, Blagys, \& Ackerman, 2006).

Although the results cited above may be suggestive of a relationship between defense mechanisms and alliance, the case has not yet been made definitively. Given the importance of 
alliance in clinical practice, we turned our attention towards exploring maladaptive defense mechanisms as measured by the DSQ, and their relationship to the development of early alliance. in a Brief Psychodynamic Intervention (BPI) setting.

Our first question pertained to whether or not the patient's maladaptive defense mechanisms would change throughout the course of the BPI. We expected a decrease in the maladaptive defense style (MDS).

The second question explored the association between patients' MDS and the therapeutic alliance. We expected that MDS score and level of alliance would be correlated.

\section{Method}

Patients. The sample $(\underline{\mathrm{N}}=68)$ included 47 women (69\%) and 21 men (31을 with a mean age of 28.54 ( $\underline{S D}=9.0)$. Patients presented mainly with diagnoses of either anxiety (42\%) or depressive (67\%) disorders. Occasionally, they were seeking help for eating (5\%), sexual (5\%) or substance abuse (2\%) disorders. The mean number of Axis 1 diagnoses was 2 diagnoses. On Axis II, 55\% presented with a personality disorder, $42 \%$ presented with a Cluster $\mathrm{C}$ personality disorder. Patients presenting with any psycho-organic or delirium disorders, substantial alcohol or drug dependence, psychotic or bipolar disorders, mental retardation, or antisocial personality disorders were excluded. 
All patients completed the four sessions of the Brief Psychodynamic Intervention (Gilliéron, 1989). The mean Global Severity Index of the SCL-90 (Derogatis, 1977) was 0.91 (SD $=$ 0.5) at the first session.

Therapists. Three female and 6 male therapists from the Adult Psychiatry Department of the University of Lausanne participated in the study. Four of them were considered to be junior therapists with less than 3 years of practice in BPI. The five other therapists were considered to be senior therapists, with more than three years of BPI practice. One therapist was a licensed psychologist while the other 8 were psychiatrists with board certification.

Treatment. The Brief Psychodynamic Intervention (BPI) is a formalized four-session assessment which focuses on the patient's initial reasons for consultation and the early interaction between the patient and the therapist. The four main objectives of BPI are: (a) developing an optimal plan to resolve the patient's crisis situation through the use of an initial dynamic interpretation, (b) establishing a psychodynamic and psychiatric diagnosis, (c) providing information on possible future therapeutic interventions, and (d) furthering the development of early alliance (Despland, Drapeau, \& de Roten, 2005). 
Instruments

Defense Style Questionnaire. The DSQ (Bond et al., 1983) is a self-report questionnaire which assesses 88 conscious derivatives of 24 defense mechanisms. Items consist of statements that are to be rated on a nine-point likert-scale (from 1 "Strongly disagree" to 9 "Strongly agree"). The patient's score for a defense mechanism is the mean of her scores on the items attributed to this mechanism. Bond (1989) grouped these 24 defense mechanisms into four factors, referred to as defense styles: (1) maladaptive, (2) imagedistorting, (3) self-sacrificing, and (4) adaptive. Each style includes two to six defense mechanisms (see Table 1). The maladaptive style includes withdrawal, regression, acting out, inhibition, passive aggression, and projection defense mechanisms. This was the only style included in the analysis because it is the only one that has been found to be stable across studies, it accounts for most of the variance in overall defensive functioning, has high internal consistency, and correlates highly with maladaptive behaviors(Bonsack, Despland, \& Spagnoli (1998). This in line with one recent and comprehensive investigation of the factor-structure of the DSQ that found evidence for a unidimensional structure of defensive functioning (Trijsburg, Van T'Spijke, Van Hesselink, \& Duivenvoorden, 2000) 
Helping Alliance Questionnaire. The Helping Alliance questionnaire (HAq-I) is a self-report measure designed to assess the patient's experience of two aspects of the alliance (Luborsky, 1976). The instrument includes 11 items assessing the patient's experience of the therapist as helpful and supportive ( 7 items) and the patient's experience of working collaboratively with the therapist towards achieving common goals ( 6 items). Every item is scored on a six-point likertscale (from -3 "No, I strongly feel that it is not true" to +3 "Yes, I strongly feel that it is true"). A patient's score is the sum of the subscale ratings. According to Hatcher and Barends (1996) the HAq-I is correlated with other wellvalidated alliance instruments (e.g., 0.74 with the CALPAS and 0.74 with the WAI) and with outcome (Martin et al., 2000). It also shows similar psychometric properties as other alliance instruments (Luborsky, 2000).

As stated above, de Roten et al. (2004) found three profiles of alliance development during BPI: High Stable alliance (HSa), Low Stable alliance (LSa), and Linear Growth alliance (LGa). Concurrent with previously stated research findings, these profiles were more predictive of outcome than a single-session measure. Thus we used them in the analysis. Data Analysis

Patients completed the questionnaires after the first and fourth interviews. Paired-sample t-tests were used to assess 
change in Maladaptive Defense style (MDS) between the first and fourth sessions. ANOVA and post hoc comparisons (Scheffe tests) were used to examine differences in MDS among the alliance profiles (HSa, LSa, LGa). We also examined changes in individual defenses using t-tests. Effect sizes of changes in defense styles and individual defenses were calculated using Cohen's d (Cohen, 1988). Post-treatment Pearson correlations were calculated to provide estimates of the association between defense style and therapeutic alliance.

\section{Results}

Change in Maladaptive Defense Style

Table 2 shows that the MDS did not change between sessions 1 and 4. However, there was an interaction between change and type of alliance development profile: there was a decrease in the use of the MDS in the LGa profile, $(\underline{t}(30)=2.30, \underline{p}=$ .028 , with an effect size of $\underline{d}=0.29$. There was no difference between the three alliance profiles at the beginning of the treatment $(\underline{E}(3,66)=1.93$, ns), but there was a difference at the end of the treatment $(\underline{E}(3,65)=4.65, \underline{p}=$ $.005)$. More specifically, change in MDS in patients of the LGa profile was different from change in the LSa profile (post hoc comparison).

Table 3 shows the correlations between maladaptive defense style (before and after the treatment) and the therapeutic 
alliance (measured at session 1. and session 4). No significant correlations were found between MDS and alliance at session 2, session 3, and mean alliance.

Change in individual defenses

When examining all three alliance profiles together, two of the 21 defenses changed: Acting out decreased, $(\underline{t}(67)=$ $0.27, \underline{\mathrm{p}}=.033)$, and anticipation increased $(\underline{t}(67)=-0.51, \underline{\mathrm{p}}=$ $.042)$. In the LGa profile, help rejecting complaining $(\underline{t}(30)=$ $0.77, \underline{p}=.010)$, projection $(\underline{t}(30)=0.31, \underline{p}=.027)$, and projective identification $(\underline{t}(30)=0.94, \underline{p}=.033)$ decreased. Defenses remained unchanged in both the HSa and LSa profiles.

The largest correlation between individual defenses and alliance was found between help rejecting complaining and alliance in the 4th session, both for the whole sample ( $\underline{r}=$ $.29, \underline{p}=.01)$ and for the LGa profile $(\underline{r}=-.44, \underline{p}=.01)$.

\section{Discussion}

We explored change in the maladaptive defense style and individual defenses over the course of a Brief Psychodynamic Intervention. Our first hypothesis was that the maladaptive defense style (i.e., withdrawal, regression, acting out, inhibition, passive aggression, and projection) would decrease over the course of the BPI. Our findings support only partialy this hypothesis. Only patients in one alliance group (the linear growth profile) showed a decreased use of the 
maladaptive defense style, though the effect size was small. In this subgroup, help rejecting complaining, projective identification, and projection decreased significantly. Drapeau et al. (2003) investigated the stability of defensive functioning in an earlier study using the same sample. They measured defensive functioning using the Defense Mechanism Rating Scale (Perry, 1990), and found an increase in the use of obsessional defenses (i.e., isolation, intellectualization, and undoing) and a decrease in the use of narcissistic defenses (i.e., omnipotence, idealization, and devaluation). Low level defenses remained stable. Studies that explored the convergent and discriminant validity of observerrated (DMRS) and self-report (DSQ) defensive functioning showed that the two instruments correlated only moderately (Perry et al., 1998; Bond et al., 1989). According to Bond et al. (1989), an explanation for this might be that the DSQ differentiates the use of a maladaptive, immature defense style from other, more mature styles, whereas the DMRS allows for more subtle differentiations in individual defenses and defensive levels.

The DSQ measures the patients' own perceptions of their defense styles, but not their actual defense mechanisms. Selfappraisal of conscious derivatives of defenses might be influenced by the patients' actual distress. Bonsack, Despland and Spagnoli. (1998) found a strikingly low MDS score for the 
patients with a low (psychotic) clinical evaluation of defensive functioning, whereas clinical evaluation and MDS score correlated $(\underline{r}=-.41)$ for the other patients of the sample. They concluded that self-awareness probably played an important role in the self-evaluation, and decreased, selfawareness in the psychotic group may have led to their underestimation and subsequent under-reporting of maladaptive defense derivatives.

According to classic psychodynamic theory, defensive functioning is supposed to be stable over time, reflecting trait-like characteristics (Davidson \& MacGregor, 1998). However, changes in defensive functioning have been shown to occur in BPI as the result of state changes related to the patients' crises and the therapeutic process (Drapeau et al., 2003). We also found changes in defenses throughout the course of BPI. A change in defenses found after such a brief treatment suggests that the sensitivity of the DSQ may be indicative of acute state reactions. A psychological crisis may be seen as an intrapsychic instability brought about by life circumstances in which the individual's ability to adapt is temporarily overwhelmed (Gilliéron, 1989). Thus, the crisis echoes the patient's inner inability to change his or her self-perception, a problem, given that it is necessary for crisis resolution. The causes of the crisis are partially (projective identification) or completely (projection) 
expelled out of the patient's consciousness, and any positive action becomes another person's responsibility (withdrawal, regression, inhibition, and acting out), while the patient may attempt to provoke anger (passive aggression) or reject any suggestions presented (help rejecting complaining). As the crisis challenges the patient's usual personality organization, defense mechanisms are activated to preserve self-esteem. The patient then becomes less flexible and uses more immature defenses. The crisis and the maladaptive defenses are likely to reinforce one another. Studies have found an association between maladaptive defenses and level of stress (Bond et al., 1989) or affective symptoms (Perry and Elannery, 1990)

Our second hypothesis, that there would be a relationship between MDS and alliance level, was supported. But this relationship concerns only with the improving alliance profile, a profile characterized by a low alliance at the beginning of the BPI and a high alliance at the end of the BPI.

From a clinical point of view, defenses are activated to ward off anxiety and distress. As such, elements of the treatment might be stressful for patients. For example, meeting the therapist may increase the patient's stress, as might the interpretation of the crisis, a crucial element done to prevent the repeating of the patient's dysfunctional 
relationship pattern in the patient-therapist relationship. As the therapist and patient work through the crisis, the therapist's support and exploration may diffuse the sense of threat induced by the crisis and reduce the patient's maladaptive defense activation. The developing therapeutic alliance might reflect this collaborative work as the patient and therapist work together to understand the causes of the crisis and to find a new personal and relational equilibrium for the patient.

This exploratory study was not only limited by its sample size and statistical power. The range in clinician expertise could be a confounding variable. Results published in a previous report found no effect of therapists' experience on the development of alliance, which suggests that this might not have greatly impacted the results of the current study (de Roten et al., 2004). External validity may not have been compromised given that patients presented with a wide range of disorders, representing a typical caseload. However, the present study was not able to control the potential confounding effect of using the DSQ, given its limitations as a self-report measure. As such, using it may pose conceptual problems due to social desirability, and the fact that defenses are difficult to observe in oneself given that they occur largely outside of conscious awareness. A step taken to minimize this potential problem was by the implementation of 
exclusion criteria that restricted participation from patients with minimal self-awareness (e.g., psychotics).

The limitations of this research might be addressed in future research using other methods of defense evaluation like observer-rated measures. Nonetheless, findings suggest preliminary estimates. Studies with a pre-post design are also needed to explore the causal relationship between changes in defenses and alliance in the course of psychotherapeutic intervention. 


\section{Reference}

Akkerman, K., Lewin, T. J., \& Carr, V. J. (1999). Long term changes in defense style among patients recovering from major depression. Journal of Nervous \& Mental Disease, $187,80-87$.

Albucher, R. C., Abelson, J. L., \& Nesse, R. M. (1998).

Defense Mechanism Changes in Successfully Treated Patients With Obsessive-Compulsive Disorder. American Journal of Psychiatry, 155, 558-559.

Bond, M., Gardner, S. T., Christian, J., \& Sigal, J. J. (1983). Empirical study of self-rated defense styles. Archives of General Psychiatry, 40, 333-338.

Bond, M. \& Perry, J. C. (2004). Long-Term Changes in Defense Styles With Psychodynamic Psychotherapy for Depressive, Anxiety, and Personality Disorders. American Journal of Psychiatry, 161, 1665-1671.

Bond, M., Perry, J. C., Gautier, M., Golderberg, M., Oppenheimer, J., \& Simand, J. (1989). Validating the self-report of defense styles. Journal of Personality Disorders, 3, 101-112.

Bonsack, C., Despland, J. N., \& Spagnoli, J. (1998). The Erench version of the Defense style Questionnaire. Psychotherapy \& Psychosomatics, 67, 24-30. DOI : $10.1159 / 000012255$ 
Cohen, J. (1988). Statistical Power Analysis for the Behavioral Sciences. Hillsdale, NJ: Lawrence Erlbaum Associates.

Davidson, K. \& MacGregor, M. W. (1998). A critical appraisal of self-report defense mechanism measures. Journal of Personality Disorders, 66, 965-992.

de Roten, Y., Fischer, M., Drapeau, M., Beretta, V., Kramer, U., Favre, N., \& Despland, J. N. (2004). Is one assessment enough? Patterns of helping alliance development and outcome. Clinical Psychology and Psychotherapy, 11, 324-331. DOI: 10.1002/cpp.420 Derogatis, L. R. (1977). SCL-90-R (revised) version manual I. Baltimore: John Hopkins University School of Medicine. Despland, J. N., Roten, Y. de., Despars, J., Stigler, M., \& Perry, J. C. (2001). Contribution of patient defense mechanisms and therapist interventions to the development of early therapeutic alliance in a brief psychodynamic investigation. Journal of Psychotherapy Practice \& Research, 10, 155-164.

Despland, J.N., Drapeau, M., \& de Roten, Y. (2005). A Naturalistic Study of the Effectiveness of a Four-Session Format: The Brief Psychodynamic Intervention, Brief Treatment and Crisis Intervention, 5, 368-378. DOI : $10.1093 /$ brief-treatment/mhi026 
Drapeau, M., de Roten, Y., Perry, J. C., \& Despland, J. N. (2003). A study of stability and change in defense mechanisms during a brief psychodynamic investigation. The Journal of Nervous and Mental Disease, 191, 496-502. DOI: $10.197 / 01 . \mathrm{nmd} .0000082210 .76762 . \mathrm{ec}$

Elannery, R. B., Jr. \& Perry, J. C. (1990). Self-rated defense style, life stress, and health status: an empirical assessment. Psychosomatics, 31, 313-320.

Foreman, S. A. \& Marmar, C. R. (1985). Therapist actions that adress initially poor therapeutic alliances in psychotherapy. American Journal of Psychiatry, 142, 922926.

Gilliéron, E. (1989). Short psychotherapy interventions (four sessions). Psychotherapy \& Psychosomatics, 51, 32-37. Hatcher, R. L. \& Barends, A. W. (1996). Patients' view of the alliance in psychotherapy: Exploring factor analysis in three alliance measures. Journal of Consulting and Clinical Psychology, 64, 1326-1336.

Hersoug, A. G., Monsen, J., Havik, O. D., \& Hoglend, P. (2002). Quality of Early Working Alliance in Psychotherapy: Diagnoses, Relationship and Intrapsychic Variables as Predictors. Psychotherapy \& Psychosomatics, $71,18-27$. DOI: $10.1159 / 000049340$

Hilsenroth, M., Peters, E., \& Ackerman, S. (2004). The Development of Therapeutic AllianceDuring Psychological 
Assessment: Patient and Therapist Perspectives Across Treatment. Journal of Personality Assessment, 83, 332344 .

Horvath, A. O. \& Bedi, R. P. (2002). The alliance. In

J.C.Norcross (Ed.), Psychotherapy relationship that work (pp. 37-70). New York: Oxford University Press. Horvath, A. O. \& Luborsky, L. (1993). The role of the therapeutic alliance in psychotherapy. Journal of Consulting \& Clinical Psychology, 61, 561-573.

Horvath, A. O. \& Symonds, B. D. (1991). Relation between working alliance and outcome in psychotherapy: a metaanalysis. Journal of Counseling Psychology, 38, 139-149. Lieberman, P. B., Wiitala, S. A., Elliott, B., McCormick, S., \& Goyette, S. B. (1998). Decreasing Length of Stay: Are There Effects on Outcomes of Psychiatric Hospitalization? American Journal of Psychiatry, 155, 905-909.

Linda S.Mullen, Carlos Blanco, Susan C.Vaughan, Roger Vaughan, \& Steven P.Roose (1999). Defense mechanisms and personality in depression. Depression and Anxiety, 10, $168-174$.

Luborsky, L. (1976). Helping alliances in psychotherapy: The grounded work for a study of their relationship to its outcome. In J.L.Claghorn (Ed.), Successful psychotherapy (pp. 92-116). New York: Brunner/Mazel. 
Luborsky, L. (2000). A pattern-setting therapeutic alliance study revised. Psychotherapy Research, 10, 17-29. DOI: $10.1093 / \mathrm{ptr} / 10.1 .17$

Marmar, C. R., Weiss, D. S., \& Gaston, L. (1989). Toward the validation of the California Therapeutic Alliance Rating System. Psychological Assessment, 1, 46-52.

Martin, D. J., Garske, J. P., \& Davis, K. (2000). Relation of the therapeutic alliance with outcome and other variables: A meta-analytic review. Journal of Consulting \& Clinical Psychology, 68, 438-450. DOI:10.1037//0022$006 \mathrm{X} \cdot 68.3 .438$

Mullen, L. S., Blanco, C., Vaughan, S. C., Vaughan, R., \& Roose, S. P. (1999). Defense mechanisms and personality in depression. Depression and Anxiety,10, 168-174.

Perry, J.C. (1990). The Defense Mechanisms Rating Scales, (5th edition). Cambridge, MA: Cambridge Hospital.

Perry, J.C. \& Cooper, S.H. (1989). An empirical study of defense mechanisms, Archives of General Psychiatry, 46, $444-452$

Perry, J. C., Banon, E., \& Ianni, E. (1999). Effectiveness of psychotherapy for personality disorders. The American Journal of Psychiatry, 156, 1312-1321.

Perry, J. C. \& Hoglend, P. (1998). Convergent and discriminant validity of overall defensive functioning. Journal of Nervous \& Mental Disease, 186, 529-535. 
Perry, J. C. \& Ianni, F. (1998). Observer-rated measures of defense mechanisms. Journal of Personality Disorders, 66, $993-1024$

Siefert, C. J., Hilsenroth, M. J., Weinberger, J., Blagys, M. D. \& Ackerman, S. J. (2006). The relationship of patient defensive functioning and alliance with therapist technique during short-term psychodynamic psychotherapy. Clinical Psychology and Psychotherapy, 13, 20-33. Trijsburg, R. W., Van T' Spijker, A., Van Henricus, L., Hesselink, A. J., \& Duivenvoorden, H. J. (2000). Measuring Overall Defensive Functioning with the Defense Style Questionnaire: A Comparison of Different Scoring Methods. Journal of Nervous \& Mental Disease. 188, 432439.

Vaillant, G. E., Bond, M., \& Vaillant, C. O. (1986). An empirically validated hierarchy of defense mechanisms. Archives of General Psychiatry, 43, 786-794. Vaillant, G. E. (1992). Ego mechanisms of defense: A guide for Clinicians and researchers. Washington, DC: American Psychiatric Association. 
Table 1

Defense styles

\begin{tabular}{ll}
\hline Style & Defenses \\
\hline Maladaptive action patterns & Acting out, Passive aggression, \\
& Regression, Withdrawal, \\
& Inhibition, Projection \\
& Pseudoaltruism, Reaction \\
Image-distorting defenses & formation \\
& Omnipotence, Devaluation, \\
Self-sacrificing defenses & Primitive idealization, \\
& Splitting \\
& Humor, Sublimation, Suppression \\
\hline
\end{tabular}

Note. From Bond (1989). 
Table 2

Change in maladaptive defense style, in alliance scores, and therapeutic alliance patterns

\begin{tabular}{|c|c|c|c|c|c|c|c|c|c|c|c|c|c|c|}
\hline & \multicolumn{6}{|c|}{ Defense maladaptive style } & \multicolumn{8}{|c|}{ Alliance } \\
\hline & \multicolumn{2}{|c|}{ Before } & \multicolumn{2}{|c|}{ After } & \multirow[b]{2}{*}{$t$} & \multirow[b]{2}{*}{$d$} & \multicolumn{2}{|c|}{ Session 1} & \multicolumn{2}{|c|}{ Session 2} & \multicolumn{2}{|c|}{ Session 3} & \multicolumn{2}{|c|}{ Session 4} \\
\hline & $\mathrm{M}$ & $S D$ & M & $S D$ & & & $\mathrm{M}$ & $\mathrm{SD}$ & M & $\mathrm{SD}$ & $\mathrm{M}$ & $S D$ & $\mathrm{M}$ & SD \\
\hline Whole sample & 4.62 & 1.1 & 4.53 & 1.1 & 1.00 & 0.07 & 11.40 & 9.0 & 13.99 & 8.6 & 16.47 & 9.7 & 18.38 & 9.9 \\
\hline \multicolumn{15}{|c|}{ Alliance patterns } \\
\hline $\mathrm{LGa}$ & 4.57 & 1.0 & 4.30 & 0.8 & $2.30 *$ & 0.29 & 8.06 & 6.2 & 13.97 & 5.7 & 18.84 & 6.2 & 22.58 & 4.5 \\
\hline $\mathrm{HSa}$ & 4.34 & 1.1 & 4.28 & 1.3 & 0.42 & 0.05 & 21.95 & 3.8 & 22.16 & 4.7 & 23.11 & 5.3 & 24.26 & 5.0 \\
\hline $\mathrm{LSa}$ & 4.99 & 1.0 & 5.21 & 1.1 & -1.48 & 0.22 & 6.00 & 7.8 & 5.39 & 7.6 & 5.39 & 9.3 & 4.94 & 7.9 \\
\hline
\end{tabular}

Note. LGa = Linear growth alliance $(\mathrm{N}=31)$, HSa $=$ High Stable alliance $(\mathrm{N}=19)$, LSa $=$ Low Stable alliance $(\mathrm{N}=18)$; tt $=$ treatment

${ }^{*} \mathrm{p}<.05 ; * * \mathrm{p}<.01$ 
Table 3

Correlations between alliance and Maladaptive defense styles

\begin{tabular}{|c|c|c|}
\hline \multirow[b]{2}{*}{ Maladaptive style } & \multicolumn{2}{|c|}{ Alliance } \\
\hline & Session 1 & Session 4 \\
\hline Whole sample $(\mathrm{N}=68)$ & & . \\
\hline Before ttt & -.051 & $-.301 *$ \\
\hline After ttt & -.105 & $-.435 * *$ \\
\hline Alliance patterns & & \\
\hline $\operatorname{LGa}(\mathrm{N}=31)$ & & \\
\hline Before ttt & .137 & $-.330^{\mathrm{a}}$ \\
\hline After ttt & -.105 & $-.398 *$ \\
\hline $\operatorname{HSa}(N=19)$ & & \\
\hline Before ttt & .104 & .066 \\
\hline After ttt & -.072 & -.083 \\
\hline $\operatorname{LSa}(N=18)$ & & \\
\hline Before ttt & .147 & -.311 \\
\hline After ttt & .312 & -.224 \\
\hline
\end{tabular}

Note. LGa = Linear growth alliance, HSa = High Stable alliance, LSa = Low Stable alliance; ttt = treatment

${ }^{\star} \mathrm{p}<.05 ;{ }^{\star}{ }^{\star} \mathrm{p}<.01 ;{ }^{\mathrm{a}} \mathrm{p}=.07$ 